\title{
Role of endometrial thickness in natural and stimulated cycles in infertility
}

\author{
Vandana Dhama*, Kiran Kumari, Rachna Chaudhary, Shakun Singh
}

Department of Obstetrics and Gynecology, Lala Lajpat Rai Memorial, Medical College, Meerut, Uttar Pradesh, India

Received: 23 April 2020

Accepted: 29 May 2020

\section{*Correspondence:}

Dr. Vandana Dhama,

E-mail: vandanallrm@yahoo.com

Copyright: () the author(s), publisher and licensee Medip Academy. This is an open-access article distributed under the terms of the Creative Commons Attribution Non-Commercial License, which permits unrestricted non-commercial use, distribution, and reproduction in any medium, provided the original work is properly cited.

\begin{abstract}
Background: The endometrium plays an important role in infertility. The growth of endometrium depends on serum oestradiol level and blood flow to the uterus. A thin endometrium is defined as a lining of less than $7 \mathrm{~mm}$ which is associated with infertility. The endometrium is best seen on Transvaginal scan (TVS). The purpose of this study was to evaluate the role of endometrial thickness and its outcome in natural and stimulated cycles in infertile women.

Methods: This prospective cohort study was conducted from June 2018 to May 2019 in LLRM Medical College Meerut, Uttar Pradesh, India. Total 150 infertile women of age less than 35 years presented with either primary or secondary infertility were enrolled. Each patient was undergoing transvaginal scan (TVS) to measure endometrial thickness follicular monitoring.

Results: The endometrial thickness and pregnancy rate was higher in letrozole induced group as compared to clomiphene with estradiol valerate and clomiphene with sildenafil citrate induced group.

Conclusions: Letrozole had better effect on endometrial thickness and pregnancy rate as compared to clomiphene citrate with estradiol valerate and clomiphene citrate with sildenafil citrate.
\end{abstract}

Keywords: Clomiphine citrate, Endometrial thickness, Letrozole, Sildenafil citrate

\section{INTRODUCTION}

Infertility is defined as- If a couple fails to achieve pregnancy after 1 year of unprotected and regular intercourse. There are many causes that result infertility out of which thin endometrium also result infertility. Most common cause of female infertility is ovulatory dysfunction. Three important factors that affect the growth of the endometrium-serum estradiol levels, blood flow to the uterus and health of the endometrial tissue (previous injuries or infections). ${ }^{1,2}$ The normal endometrium changes in appearance as well as in thickness throughout the menstrual cycle. In the menstrual and early proliferative phase, it is a thin, brightly echogenic line comprising of the basal layer, minimal fluid can be seen within the endometrium in the menstrual phase. In the late proliferative phase, it develops a trilaminar appearance: outer echogenic basal layer, middle hypoechoic functional layer, and an inner echogenic line at the central interface. In the secretory phase it is at its thickest, up to $16 \mathrm{~mm}$, and becomes uniformly echogenic/ as the functional layer becomes oedematous and isoechoic to the basal layer, (Figure 1). ${ }^{3}$

The aim of this study was to compare the endometrial thickness and pregnancy rate in natural and stimulated cycles in infertility.

\section{Objectives}

- To evaluate the effects of various drugs on endometrial thickness and its outcome in cohort of infertile women.

- To study the effect of endometrial thickness on the reproductive outcome.

- To study the clinical pregnancy rates. 

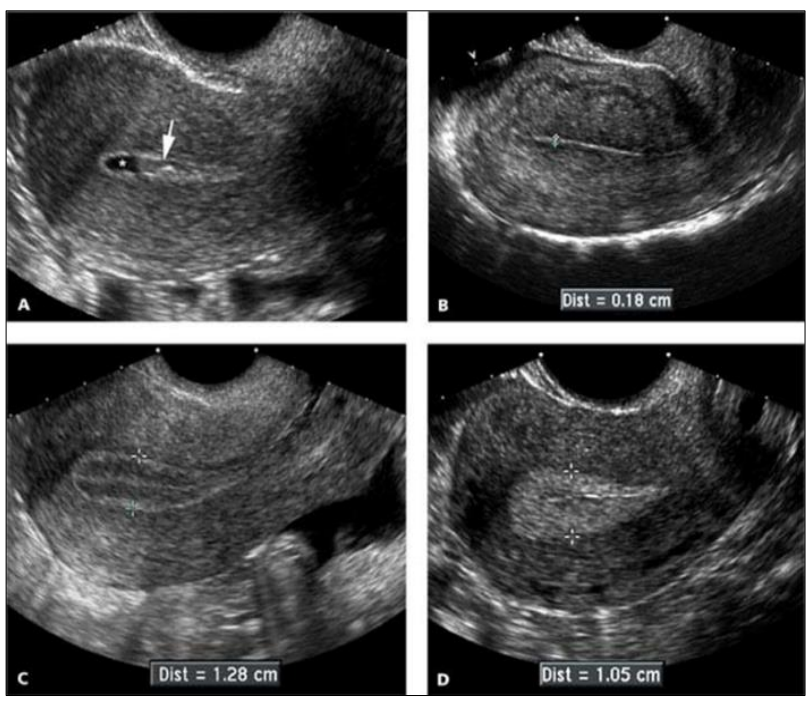

Figure 1: Endometrium in various phases of menstrual cycle trilaminar appearance in late proliferative phase.

\section{METHODS}

This study was conducted in the department of obstetrics and gynecology LLRM Medical College and associated S. V. B. P. Hospital Meerut, Uttar Pradesh, India during 1-year period from May 2018 to June 2019. This was a prospective cohort study comprises of 150 women who will fulfil the selection criteria attending gynecology OPD. The study protocol will be put for approval by the institutional ethic committee. All subject will be included in the study after obtaining an informed and written consent. Participation in the study was voluntary. 150 infertile women of age less than 35 years were randomly divided into two groups.

\section{Control group}

- Women in whom ovulation induction drugs was not given (50 women's).

\section{Case group}

- Women in whom ovulation induction drugs was given (100 women).

\section{Inclusion criteria}

All patients with primary and secondary infertility who fulfill the following criteria.

- A cohort of 150 infertile women shall be taken for study

- Infertile women with who grade II infertility

- Infertile women of age less than 35 years with normal ovarian reserve

- Normal sperm analysis
- Duration of infertility less than 7 years.

\section{Exclusion criteria}

- $\mathrm{B} / \mathrm{L}$ tubal blockage due to any reason

- Endometriosis III and IV grade

- All cases of hypogonadotropic- hypogonadism WHO I and hypergonadotropic - hypogonadism WHO III infertility

- Abnormal sperm analysis

- Recurrent miscarriages

- Mullerian anomaly.

Each patient underwent transvaginal ultrasonography in a quiet and comfortable position. Patients were asked to empty their bladder. First transvaginal ultrasonography was done on menstrual cycle day 2 to measure endometrial thickness and antral follicle count, if not on day 2 then on any days between day 3 and day 8. Then the patient was asked to report on day 9 and then alternate day monitoring was done to measure endometrial thickness with follicular monitoring until the estimated day of ovulation. Patients were given HCG injection intramuscular till mature follicle becomes more than $18 \mathrm{~mm}$ in size. After follicle ruptured. Luteal phase support was given with micronized progesterone SR 300 $\mathrm{mg}$ for 10 days. The patients were advised regarding the timing of intercourse and were asked to report in case of missed period or on the second day of coming menses. Urine pregnancy test was done if the patient missed any period and was reported to be positive or negative.

\section{RESULTS}

This study included 150 infertile women of age less than 35 years with primary and secondary infertility.

Table 1: Distribution of cases according to type of infertility.

\begin{tabular}{|lll|}
\hline $\begin{array}{l}\text { Type of } \\
\text { infertility }\end{array}$ & $\begin{array}{l}\text { No. of cases } \\
(\mathbf{N}=150)\end{array}$ & Percentage \\
\hline Primary & 96 & $64 \%$ \\
\hline Secondary & 54 & $36 \%$ \\
\hline Total & 150 & $100 \%$ \\
\hline
\end{tabular}

In this study out of 150 patients most of the patients 96 $(64 \%)$ were of primary infertility and rest were $54(36 \%)$ secondary fertility (Table 1). According to primary infertility and secondary infertility are, majority of patients were found in 25-29 years age group i.e., 41 $(42.71 \%)$ and $34(62.96 \%)$ in primary infertility and secondary infertility respectively followed by $30-34$ years age group i.e., $29(30.21 \%)$ and $10(18.52 \%)$ in primary infertility and secondary infertility. Minimum patients were found in 20-24 years age group i.e., 26 (27.08\%) in primary infertility and $10(18.52 \%)$ in secondary infertility (Table 2). 
Table 2: Distribution of female patients according to age.

\begin{tabular}{|lllllll|}
\hline \multirow{2}{*}{ Age (in years) } & \multicolumn{2}{l}{ Total patients } & \multicolumn{2}{c|}{ Primary infertility } & \multicolumn{2}{c|}{ Secondary infertility } \\
\cline { 2 - 7 } & No. & $\mathbf{\%}$ & No. & \% & No. & \% \\
\hline $20-24$ & 36 & $24 \%$ & 26 & $27.08 \%$ & 10 & $18.52 \%$ \\
\hline $25-29$ & 75 & $50 \%$ & 41 & $42.71 \%$ & 34 & $62.96 \%$ \\
\hline $30-34$ & 39 & $26 \%$ & 29 & $30.21 \%$ & 10 & $18.52 \%$ \\
\hline Total & 150 & $100 \%$ & 96 & $100 \%$ & 54 & $100 \%$ \\
\hline
\end{tabular}

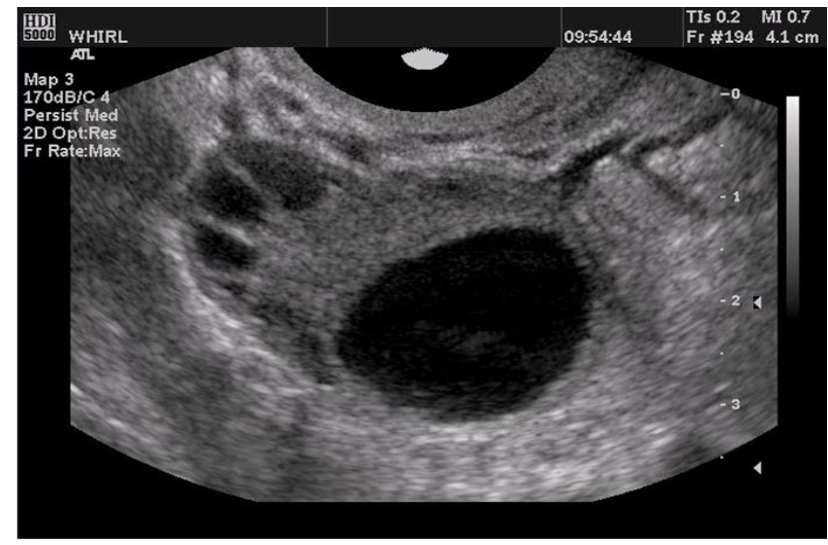

Figure 2: A dominant follicle just about to rupture.

In this study maximum number of cases $103(68.67 \%)$ had infertility of 4-6 years duration and rest $47(31.33 \%)$ were in 1-3 years of duration (Table 3). Out of 150 cases, all patients are divided in two groups, spontaneous cycles (50) and induced cycles (100). Out of 50 patients of spontaneous cycles, majority of patients were found in 21-22 $\mathrm{mm}$ size i.e., 23 (46\%) followed by $18-20 \mathrm{~mm}$ size i.e., $14(28 \%)$ and minimum patients were found in $>24$ $\mathrm{mm}$ size group i.e., $6(12 \%)$. While in induced cycles, majority of patients were found in $23-24 \mathrm{~mm}$ size i.e., 48 (48\%) followed by $21-22 \mathrm{~mm}$ size i.e., 22 (22\%) and minimum patients were found in $18-20 \mathrm{~mm}$ group i.e., 14 (14\%) (Table 4), (Figure 2).

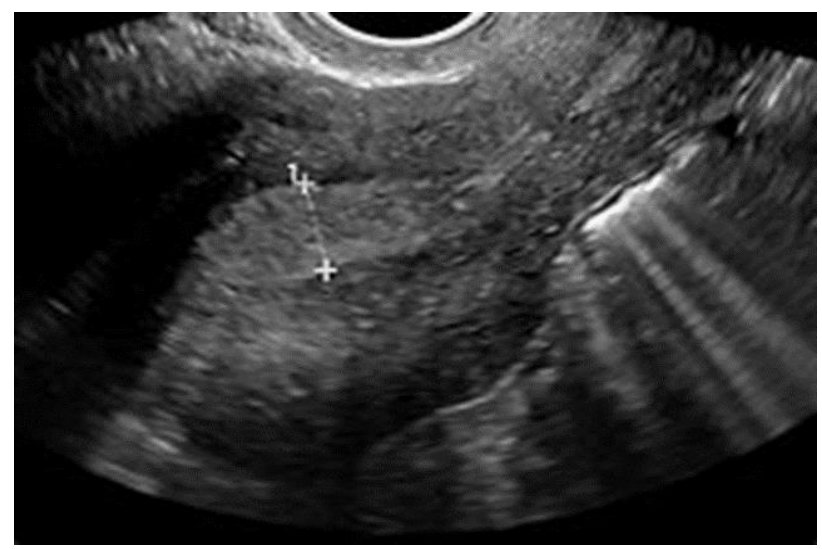

Figure 3: How to measure endometrial thickness.

In this study out of 150 total patients, taken 50 patients in spontaneous cycle and 100 patients in induced cycle. Out of 50 patients of spontaneous cycle, majority of patients were found in endometrial thickness 7.1-8 $\mathrm{mm}$ i.e., 29 (58\%) followed by ET 8.1-9 $\mathrm{mm}$ i.e., 11 (22\%) and minimum cases of spontaneous cycle were found in ET 6-7 $\mathrm{mm}$ and $>10 \mathrm{~mm}$ i.e. $3(6 \%)$. Out of 100 patients of Induced cycle, majority of patients were found in endometrial thickness 9.1-10 mm i.e., 56 (56\%) followed by ET $>10 \mathrm{~mm}$ i.e., 24 (24\%), minimum $0(0 \%)$ cases of induced cycle were found in ET 6-7 $\mathrm{mm}$ and 7.1-8 $\mathrm{mm}$ i.e., $0(0 \%)$ (Table 5), (Figure 3).

Table 3: Distribution of cases according to duration of infertility.

\begin{tabular}{|lll|}
\hline Duration in years & No. of cases & Percentage \\
\hline $1-3$ & 47 & $31.33 \%$ \\
\hline $4-6$ & 103 & $68.67 \%$ \\
\hline Total & 150 & $100 \%$ \\
\hline
\end{tabular}

Table 4: Maximum size of preovulatory dominant follicle.

\begin{tabular}{|c|c|c|c|c|}
\hline \multirow{2}{*}{ Size (in mm) } & \multicolumn{2}{|c|}{ Spontaneous cycle } & \multicolumn{2}{|c|}{ Induced cycle } \\
\hline & No. of cases & $\%$ & No. of cases & $\%$ \\
\hline $18-20$ & 14 & $28 \%$ & 16 & $16 \%$ \\
\hline $21-22$ & 23 & $46 \%$ & 22 & $22 \%$ \\
\hline $23-24$ & 7 & $14 \%$ & 48 & $48 \%$ \\
\hline$>24$ & 6 & $12 \%$ & 14 & $14 \%$ \\
\hline Total & 50 & $100 \%$ & 100 & $100 \%$ \\
\hline Mean \pm SD & $21.56 \pm 2.25$ & & $22.67 \pm 2.29$ & \\
\hline
\end{tabular}


Table 5: Endometrial thickness on USG on the day of ovulation.

\begin{tabular}{|lllll|}
\hline Endometrial thickness (MM) & Spontaneous cycle & \multicolumn{2}{l|}{ Induced cycle } \\
\cline { 2 - 4 } & No. & $\mathbf{\%}$ & No. & \% \\
\hline $6-7$ & 2 & $4 \%$ & 0 & $0 \%$ \\
\hline $7.1-8$ & 29 & $58 \%$ & 0 & $0 \%$ \\
\hline $8.1-9$ & 11 & $22 \%$ & 20 & $20 \%$ \\
\hline $9.1-10$ & 5 & $10 \%$ & 56 & $56 \%$ \\
\hline$>10$ & 3 & $6 \%$ & 24 & $24 \%$ \\
\hline Total & 50 & $100 \%$ & 100 & $100 \%$ \\
\hline Mean \pm SD & $8.33 \pm 1.28$ & & $9.80 \pm 0.91$ & \\
\hline
\end{tabular}

Table 6: Correlation with ovulation rate of spontaneous cycle $(n=50)$, clomiphene citrate $(n=50)$ and letrozole $(\mathbf{n}=\mathbf{5 0})$.

\begin{tabular}{|lllllll|}
\hline & \multicolumn{2}{l}{ Spontaneous cycle $(\mathbf{n}=\mathbf{5 0})$} & \multicolumn{2}{c|}{ Clomiphene citrate $(\mathbf{n}=\mathbf{5 0})$} & \multicolumn{2}{c|}{ Letrozole $(\mathbf{n}=\mathbf{5 0})$} \\
\hline Nov of cases & No. & $\mathbf{\%}$ & No. & $\mathbf{\%}$ & No. & $\mathbf{\%}$ \\
\hline Ovo-ovulion & 38 & $76 \%$ & 44 & $88 \%$ & 48 & $96 \%$ \\
\hline Total & 12 & $24 \%$ & 6 & $12 \%$ & 2 & $4 \%$ \\
\hline p-value & 50 & $100 \%$ & 50 & $100 \%$ & 50 & $100 \%$ \\
\hline
\end{tabular}

Table 7: Relationship between endometrial thickness and pregnancy rate in spontaneous and induced cycle.

\begin{tabular}{|lllll|}
\hline \multirow{2}{*}{ Endometrial thickness } & \multicolumn{2}{l|}{ Spontaneous cycle $(\mathbf{n = 5 0})$} & \multicolumn{2}{l|}{ Induced cycle $(\mathbf{n = 1 0 0})$} \\
\cline { 2 - 5 } & Pregnancy & No pregnancy & Pregnancy & No pregnancy \\
\hline 7-8 mm & 1 & 29 & 0 & 0 \\
\hline $8.1-10 \mathrm{~mm}$ & 2 & 15 & 18 & 64 \\
\hline Total $(\mathrm{n}=150)$ & 3 & 47 & 20 & 80 \\
\hline p-value & 0.028 & & & \\
\hline
\end{tabular}

Out of total 150 cases, they were divided to spontaneous cycle $(n=50)$, clomiphene citrate $(n=50)$ and letrozole $(n=50)$ simultaneously. Majority of ovulation was occurring with letrozole i.e., 48 (96\%) followed by clomiphene citrate i.e., $44(88 \%)$. Minimum ovulation occurs with spontaneous cycles i.e., 38 (76\%) (Table 6).

In this study majority of pregnancy were found in Induced cycles i.e., 18 with 8.1-10 mm ET followed by 2 pregnancy with $>10 \mathrm{~mm}$ ET. In the spontaneous cycles, maximum 2 pregnancies were found with ET 8.1-10 mm followed by 1 pregnancy with ET 7-8 $\mathrm{mm}$ (Table 7).

\section{DISCUSSION}

Endometrial thickness plays an important role in infertility. The growth of the endometrium depends on serum estradiol level and blood flow to the uterus.

Thin endometrium less than $7 \mathrm{~mm}$ is associated with a low pregnancy rate. estradiol valerate increases growth of the endometrium in proliferative phase and sildenafil citrate increases endometrial growth by increasing blood flow to the uterus.
Disorder of ovulation is an important contributor to the problem of infertility. With the development of large range of ovulation induction drugs, the treatment of ovulatory dysfunction has become more effective and successful. clomiphene citrate, first used in 1960s was introduced by Greenblatt. It is one of the most commonly used ovulation induction agents.

Letrozole appears to be more effective ovulation induction agent than the standard drug clomiphene citrate to achieve pregnancy supported by the National Institute of Health. Earlier, ovulation was monitored by vague tests like rise in basal body temperature, serum estradiol level and LH surge. With the advent of transvaginal sonography (TVS), a simple and non-invasive method to study ovulation has been established.

The present study was conducted on 150 patients suffering from infertility. In all these patients follicular monitoring was done and after that 100 patients were induced for the number of cycles.

This study was conducted with main aim to assess the thickness of endometrium sonographically for normal pregnancy in natural and stimulated cycles in infertility. 
This study showed Out of 150 patients most of the patients $96(64 \%)$ were of primary infertility and rest were $54(36 \%)$ secondary fertility.

In this study majority of patients were found in 25-29 years age group i.e., $41(42.71 \%)$ and 34 (62.96\%) in primary infertility and secondary infertility respectively followed by $30-34$ years age group i.e., 29 (30.21\%) and $10(18.52 \%)$ in primary infertility and secondary infertility respectively. Minimum patients were found in 20-24 years age group i.e., $26(27.08 \%)$ in primary infertility and $10(18.52 \%)$ in secondary infertility.

In this study, out of 150 cases, all patients are divided in two groups, spontaneous cycles (50) and induced cycles (100). Out of 50 patients of spontaneous cycles, majority of patients were found in 21-22 mm size i.e., 23 (46\%) followed by $18-20 \mathrm{~mm}$ size i.e., 14 (28\%) and minimum patients were found in $>24 \mathrm{~mm}$ size group i.e., 6 (12\%). While in induced cycles, majority of patients were found in 23-24 mm size i.e., 48 (48\%) followed by $21-22 \mathrm{~mm}$ size i.e., $22(22 \%)$ and minimum patients were found in 18-20 mm group i.e., $16(16 \%)$.

Teramoto $\mathrm{S}$ et al, found that ovulation is reported to occur when the follicular size reaches $>18 \mathrm{~mm}^{4}$

In this study out of 150 total patients, out of 50 patients of spontaneous cycle, majority of patients were found in endometrial thickness 7.1-8 mm i.e., 29 (58\%) followed by ET $8.1-9 \mathrm{~mm}$ i.e., $11(22 \%)$ and minimum cases of spontaneous cycle were found in ET 6-7 $\mathrm{mm}$ and $>10$ mm i.e., $3(6 \%)$.

Out of 100 patients of induced cycle, majority of patients were found in endometrial thickness $9.1-10 \mathrm{~mm}$ i.e., 56 $(56 \%)$ followed by ET $>10 \mathrm{~mm}$ i.e., 24 (24\%), minimum $0(0 \%)$ cases of induced cycle were found in ET $6-7 \mathrm{~mm}$ and 7.1-8 $\mathrm{mm}$ i.e., $0(0 \%)$.

These findings are similar to findings documented by Harira $\mathrm{M}$ et al, that the endometrial thickness in induced cycle with $\mathrm{CC}+\mathrm{EV}$ was $8.28 \mathrm{~mm}$ and with letrozole 9.2 mm. ${ }^{5}$ Similar study was done by Mangal $\mathrm{S}$ et al, that endometrial thickness with estradiol valerate was 9.94 $\mathrm{mm}$ and $9.42 \mathrm{~mm}$ with sildenafil citrate. ${ }^{6}$

In the present study authors have selected patients for 3 different ovulation induction protocols. Majority of ovulation occurs in induced cycle $(n=100)$ i.e., $92(92 \%)$ and $38(76 \%)$ ovulation occurs in spontaneous cycle. Out of remaining 7 cases, $3(42.86 \%)$ cases were ovulated with CC (100 mg/day) + EV (2 mg/day) dose with ET 9.1-10 $\mathrm{mm}$ and rest $4(57.14 \%)$ cases were not ovulated.

In this study out of 25 cases, $18(72 \%)$ cases ovulated with CC (50 mg/day) + EV $2 \mathrm{mg}$ /day) dose with ET 8-9 $\mathrm{mm}$ and rest 7 (28\%) cases were not ovulated. These 4 non-ovulated patients were trying with dose of CC (150 $\mathrm{mg})+\mathrm{EV}(2 \mathrm{mg})$ with $\mathrm{ET}>10 \mathrm{~mm}$ but 4 (100\%) were found not-ovulated. These 4 non-ovulated patients come under clomiphene resistant cases.

Out of 25 cases, $19(76 \%)$ cases ovulated with CC (50 $\mathrm{mg} /$ day $)+\mathrm{SC}$ (25 mg/day) dose with ET 9.1-10 mm and rest $6(24 \%)$ cases were not ovulated. Out of remaining 6 cases, $4(66.67 \%)$ cases were ovulated with CC (100 $\mathrm{mg} /$ day $)+\mathrm{SC}$ (25 mg/day) dose with ET 10.1-11 mm and rest $2(33.33 \%)$ cases were not ovulated. These 2 nonovulated patients were tried with dose of CC $(150 \mathrm{mg})+$ SC ( $25 \mathrm{mg} /$ day) with ET $>11 \mathrm{~mm}$ but all 2 (100\%) were found not-ovulated. These 2 non-ovulated patients come under clomiphene resistant cases. These results were comparable with Budinetz $\mathrm{TH}$ et al, showing ovulation rate $(86.7 \%)$ with an increasing dose of clomiphene citrate. $^{7}$

Out of 50 cases, $36(72 \%)$ cases ovulated with letrozole (2.5 mg/day) dose with ET 9-10 $\mathrm{mm}$ and rest 14 (28\%) cases were not ovulated. Out of remaining 14 cases, 12 $(85.71 \%)$ cases were ovulated with letrozole $(5 \mathrm{mg} /$ day) dose with ET 10.1-13 mm and rest 2 (14.29\%) cases were not ovulated. This study results are comparable with those reported by Pritis EA et al, who concluded that $94.4 \%$ of patients were ovulated with a dose of 2.5 $\mathrm{mg} /$ day to $5 \mathrm{mg} /$ day of letrozole. ${ }^{8}$

Out of 150 cases, they were divided in spontaneous cycle $(n=50)$ and induced cycle $(n=100)$; majority of pregnancy were found in induced cycle (in letrozole group) i.e., 20 (20\%) while $3(6 \%)$ pregnancies were found in spontaneous cycle. These findings are similar to findings documented by Founda UM et al, reported that the pregnancy rate was higher in letrozole induced cycle $(18.96 \%)$ as compared to clomiphene induced cycle $11.43 \% .^{9}$ In this study there was positive correlation between endometrial thickness and pregnancy rate.

\section{CONCLUSION}

Thin endometrium is an infrequent but challenging occurrence in assisted reproduction. Thin endometrium less than $7 \mathrm{~mm}$ has lower pregnancy rate. For this reason, in the present study authors used two drugs esrtadiol valerate and sildenafil citrate to increase the endometrial thickness in those patients having thin endometrium for better pregnancy rate.

- In the present study authors found that sildenafil had better effect on endometrial thickness and pregnancy rate as compared to esrtadiol valerate

- One abortion was found in clomiphene with esrtadiol group

- Letrozole had good effect on endometrial thickness and pregnancy rate when compared to clomiphene citrate with esrtadiol valerate

- There was no significant difference regarding endometrial thickness when letrozole compared to clomiphene citrate with sildenafil citrate 
- Letrozole had higher pregnancy rate when compared to clomiphene citrate with sildenafil citrate

- Letrozole induced cycle had higher pregnancy rate and higher live birth rate as compared to other drugs hence it is preferred in infertility.

\section{ACKNOWLEDGMENTS}

Authors would like to thank Dr. Sonal Panchal for providing us with useful information.

Funding: No funding sources

Conflict of interest: None declared

Ethical approval: The study was approved by the Institutional Ethics Committee

\section{REFERENCES}

1. Geyter De, Schmitter, De Gayter M, Nieschlage, Holzgreve W, Shnieder HP. Prospective evaluation of the ultrasound appearance of the Endometrial in a cohort of 10186 infertile women. Fertil Steril. 2000;73:106.

2. Hung E, Carina YN, Chan CW, Tang OS, Yeung WS, Ho PC. Factors affecting endometrial and subendometrial blood flow measured by three dimensional power doppler ultrasound during IVF treatment. Human Reprod. 2006;21(4):1062-9.

3. Gupta A, Desai A, Bhatt S. Imaging of the Endometrium: physiologic changes and diseases: women's imaging. Radiolographics: a review publication of the Radiological Society of North America. Inc. 2017;37(7):2206-07.
4. Teramoto S, Osada H, Shozu M. Premature ruptured follicles often retain competent oocytes in infertile women. Sci Rep. 2019;9;1504.

5. Harira M. Use of Letrozole versus clomiphene citrate-estradiol for treating infertile women with unexplained infertility not responding well to clomiphene alone comparative study. Middle East Fertil Society J. 2018;4(23):384-7.

6. Mangal S, Mehirishi S. Compare the effect of vaginal sildenafil, estradiol valerate on endometrial thickness, blood flow and pregnancy rates in infertile women undergoing intrauterine insemination. Reprod. Contracept Obstet Gynecol. 2016;5(7);22747.

7. Budinetz TH, Griffin DW, Engmann LL, Benadiva CA, Nulsen JC, DiLuigi AJ. Ovulatory rate in subsequent clomiphene citrate (CC) cycle after 'stairstep'(SS) clomiphene citrate protocol. Fertil Steril. 2012;98(3):S170.

8. Pritts EA. Letrozole for ovulation induction and controlled ovarian hyperstimulation. Curr Opin Obstet Gyneccol. 2010;22(4):289-94.

9. Founda UM, Sayed AM. Extended letrozole regimen versus clomiphene citrate for super ovulation in patients with unexplained infertility A randomized control trial. Reprod Biol Endocrinol. 2011;84:9.

Cite this article as: Dhama V, Kumari K, Chaudhary $\mathrm{R}$, Singh S. Role of endometrial thickness in natural and stimulated cycles in infertility. Int J Reprod Contracept Obstet Gynecol 2020;9:2872-7. 